\title{
OS ASPECTOS JURÍDICOS DO COWORKING E A EFETIVIDADE DA SOLIDARIEDADE
}

\author{
Bruno Torquete Barbosa ${ }^{1}$ \\ Adeneele Garcia Carneiro ${ }^{2}$
}

\section{RESUMO}

A pesquisa trata da correlação do princípio da solidariedade com a operação de uma atividade empresarial específica, denominada coworking. Os avanços no modelo empresarial tradicional e a colaboração, alavancam a ideia espaços compartilhados entre diversos profissionais que primam pelo contato pessoal e sustentabilidade. Assim inicialmente abordase a construção histórica deste modelo empresarial, o contexto social no qual surgiu, e o tratamento legal afetos ao coworking afim de averiguar se esta nova tendência possui suficiente amparo, seja para quem disponibiliza ou utiliza os espaços, ou se há a demanda por legislação própria.

Palavras-chave: Coworking, Economia Compartilhada, Escritórios Compartilhados, Solidariedade;

\section{THE LEGAL ASPECTS OF COWORKING AND THE EFFECTIVENESS OF SOLIDARITY}

\begin{abstract}
The research deals with the correlation of the principle of solidarity with the operation of a specific business activity known as coworking. Advances in traditional business model and the collaboration, leverage the idea shared spaces between various professionals who Excel at personal contact and sustainability. So initially deals with the historical construction of this business model, the social context in which it arose, and the cool treatment affects the coworking in order to ascertain whether this new trend has enough amparo, is for anyone who provides or uses the spaces, or if there is a demand for their own legislation.
\end{abstract}

Keywords: Coworking, Shared Economics, Shared Offices, Solidarity.

\section{INTRODUÇÃO}

A sociedade em constante mudança, crises políticas e financeiras, surgimentos de novos conceitos de empresas e de oportunidades de trabalho não convencionais, são terreno fértil para novas modalidades de labor.

\footnotetext{
${ }^{1}$ Mestrando em Direito da Universidade Marília - UNIMAR, Especialista pela Universidade da Amazônia UNAMA, Professor do curso de Direito da FAIR/UNIASSELVI-Rondonópolis-MT, Advogado. torquete@hotmail.com

${ }^{2}$ Doutoranda em Direito da Universidade Marília - UNIMAR, Mestre em Direito da Universidade Marília UNIMAR, Advogada. email@adeneele.com.br
} 
Conceitos modernos de empreendimentos afastam necessidades estruturais que sempre foram determinantes para a criação e manutenção e uma empresa, ou a prestação de serviços por profissionais liberais.

Bem como o surgimento de um sentimento colaborativo, que extrapola os protocolos formais de parcerias e aglutinam atividades interdisciplinares como meio de atender um consumidor de produtos e serviços cada vez mais exigente.

Escritórios já mobiliados, os chamados escritórios virtuais, e os ambientes de coworking surgem nesse contexto de uma nova economia como alternativa estrutural para profissionais e empresas em seu início de operação, permitindo uma flexibilidade de alocação de profissionais que dispensam os investimentos naturais de um novo negócio.

Buscar-se-á com o presente trabalho analisar sob o prisma do ordenamento jurídico a afetação dessa modalidade de atividade apurando-se a necessidade de se criar um ordenamento jurídico próprio ou se interpretar essa nova realidade à legislação em vigor.

Várias são as possíveis vertentes jurídicas que envolvem os espaços de coworking, entretanto, observar-se-á uma evidente ausência de legislação específica e até de literatura jurídica. Assim, se proporá uma análise das possibilidades de aplicação de analogia ou da necessidade de produção legislativa.

O presente trabalho pretenderá utilizar como referencial teórico o princípio da solidariedade, a partir de uma análise do contexto social econômico que alimenta esta nova tendência nas organizações laborativas, buscando as possíveis implicações jurídicas.

Será apresentada uma contextualização histórica, que favorece as iniciativas colaborativas e compartilhadas, baseadas em um sentimento que nasce como um espírito de solidariedade mas se apresenta como meio de forte expressão econômica, valorizando-se a formação de times, o trabalho em equipe e a conexão interdisciplinar de diversas profissões e iniciativas empresariais.

Serão ainda apresentados os elementos que envolvem a atividade dos espaços de coworking, buscando-se entender as motivações para o exponencial crescimento desta modalidade, buscando-se sempre trazer a legislação em vigor em confronto com tais avanços.

\section{ORIGEM HISTÓRICA}


Ao chegar em seu escritório o profissional checa seus e-mails, e agenda, revisa seus compromissos diários, repassa os recados, retorna ligações, e se dirige até a copa onde toma um café enquanto conversa com o colega que se senta na mesa ao lado. Situação normal em sua rotina de trabalho, a não ser pelo fato que este profissional pode ser um advogado, e seu colega de trabalho o diretor de criatividade de uma empresa que geração de energia solar, ou um psicólogo, que aguarda seu paciente, já tendo reservado a sala de atendimento individual de um espaço de coworking

O conceito, como tantas outras tendências, nasceu nos Estados Unidos, e tem sua origem registrada como sendo no ano de 2005, e é atribuída a Brad Neuberg, entretanto, em que pese ser contestado por Neuberg atribui-se ao também norte americado Bernie DeKoven, ter descrito a ideia do trabalho compartilhado, para o desenvolvimento de software.

Permitindo-se que o próprio Neuber se apresente:

Eu sou um engenheiro sênior de software na equipe de Aprendizagem de Máquinas no Dropbox. Mais recentemente, eu construí um pipeline OCR de produção usando "deep learning" e "computer vision" para milhões de usuários no Dropbox usando TensorFlow

Eu também criei o Coworking, um movimento internacional de base para estabelecer um novo tipo de espaço de trabalho para os trabalhadores independentes. ${ }^{3}$

O prório Neuberg mantem um blog - "coding in Paradise" na internet e uma conta no Twitter, afim de corrigir o que considera um engano, não lhe atribuir o crédito pela criação do termo. Ressalvadas essa disputa da paternidade, faz-se importante, neste trabalho atribuir à Neuberg, uma vez que se busca trabalhar está em total consonância com os empreendimentos deste que mais se assemelha com o modelo atual.

Cumpre trazer as palavras do próprio, para descrever tal confusão:

Quando eu cunhei o termo coworking, fiz isso independentemente de outros termos. Cerca de um ano e meio depois, enquanto procurava

\footnotetext{
${ }^{3}$ Descrição de perfil do Linkedin, disponível em https://www.linkedin.com/in/bradneuberg/ acesso em 26 jul 2.017
} 
um nome de domínio para o coworking, tropecei em 'coworking.com' que era propriedade de Bernie De Koven. Ele não sabia nada sobre os espaços de trabalho colaborativos em que estávamos envolvidos. Ele havia iniciado um instituto chamado Instituto Coworking que parecia estar tentando aumentar a conscientização sobre técnicas e tecnologias de trabalho colaborativas. Bernie e eu nos falamos por telefone naquele momento e rimos do fato de que tínhamos, ambos, escolhido coworking para se referir às coisas diferentes que estávamos perseguindo. Nós escolhemos a mesma palavra para se referir a coisas diferentes pois de nenhuma maneira nossas iniciativas estavam conectadas. Bernie é um grande cara que fez um trabalho interessante, mas não estava relacionado com a especial ascensão do movimento do coworking. ${ }^{4}$

Cumpre esclarecer que alheio à discussão acerca do criador, destaca-se que a iniciativa é recente, e o crescimento é impressionante, pois, são pouco mais de 15 (quinze) anos se a contagem do tempo iniciar quando a utilização do termo, ou algo em torno de 12 (doze) anos, se for observado desde o que se indica como a abertura do primeiro espaço que realmente inaugura a tendência da forma como hoje se apresenta, em que pese ter havido avanços, principalmente quando profissionais de áreas não ligadas à tecnologia, e empresas também se apropriam da ideia.

Permanecendo ainda na origem história no mesmo artigo, Neuberg afirma ainda que antes do conhecido Hat Factory (criado pelo próprio), que era um espaço onde residiam três profissionais da área de tecnologia, mas que durante o dia compartilhavam com outros que

\footnotetext{
${ }^{4}$ When I coined the term coworking I did that independently of other terms. About a year and a half later while looking for a domain name for coworking for the coworking wiki I stumbled on coworking.com that was owned by Bernie De Koven. He knew nothing about the collaborative workspaces we were involved in. He had started an institute called the Coworking Institute that looked like it was trying to increase awareness of collaborative work techniques and technologies. Bernie and I briefly connected on the phone at that time and laughed about the fact that we had both chosen coworking to refer to the different things we were pursuing. We chose the same word to refer to different things that we were doing but in no way were our initiatives connected. Bernie's a great guy who's done interesting work but was unconnected with the rise of the coworking space movement. (The Start of Coworking (from the Guy that Started It), disponível em http://codinginparadise.org/ebooks/html/blog/start_of_coworking.html Acesso em: 25 jul. 2.017)
} 
pretendessem trabalhar junto e interagir criando essa conectividade, este já havia empreendido anteriormente, na mesma área, havendo criado antes o San Francisco Coworking Space.

O primeiro espaço de coworking era o San Francisco Coworking Space no Spiral Muse (não a Hat Factory, como foi erroneamente). Eu tive vários amigos envolvidos no espaço Spiral Muse, que era um coletivo feminista no distrito de Mission em San Francisco. ${ }^{5}$

A palavra em si define o modelo de negócio onde se compartilha gastos com energia, acesso à internet, linha telefônica, serviços de secretaria e copa, dentre outros serviços.

Existe grande divergência nos estudos quando se busca estimar quantos espaços de Coworking existem no Brasil, por razões óbvias, uma vez que não há um único modelo de negócio definido, mas diversas possibilidades, entretanto, em que pese tais divergências é importante citar o levantamento do Censo Coworking 2017, realizado pelo Coworking Brasil e Ekonomio-Movebla ${ }^{6}$ que estimam haver aproximadamente 810 espaços ativos no Brasil, que juntos disponibilizam 56 mil estações de trabalho, número este que cresce diariamente.

Se analisado sob um olhar macro, nada se observa de novo, uma vez que a divisão de tais despesas há muito já é feita principalmente por profissionais como médicos ou advogados, que alugam um espaço que tenha várias salas, e em que pese cada um ocupar seu espaço individual os custos de manutenção do espaço são compartilhados por todos.

Ou ainda pode-se se pensar em um condomínio, onde os gastos com limpeza de áreas comuns, elevador, portaria, e a própria administração é rateada entre os moradores.

A grande diferença dessa modalidade é a potencialização do ócio como meio de gerar riqueza, o que será tratado nos próximos capítulos.

\section{NOVO CONTEXTO SOCIAL FAVORÁVEL}

\footnotetext{
${ }^{5}$ The first coworking space was the San Francisco Coworking Space at Spiral Muse (not the Hat Factory as has been misprinted sometimes). I had several friends involved in the Spiral Muse space, which was a feminist collective in the Mission district in San Francisco. (The Start of Coworking (from the Guy that Started It), disponível em http://codinginparadise.org/ebooks/html/blog/start_of_coworking.html Acesso em: 25 jul. 2017

${ }^{6}$ Censo Coworking 2017 - Disponível em https://coworkingbrasil.org/censo/2017/ Acesso em 25 jul. 2017 
É importante que se lembre que muitas vezes há uma necessidade de se adquirir um produto com o único objetivo de se obter o serviço que aquele produto disponibiliza, um exemplo clássico é a furadeira, que não é adquirida para se possuir o produto, excetuados é claro os profissionais que dela se utilizam como ferramenta de trabalho. Mas é um produto que custa um valor considerável, que possui um certo volume, sendo necessário se buscar um espaço para que o mesmo seja guardado, e que será utilizado, renovando-se a ressalva acima, por pouquíssimas horas no decorrer de um ano.

Ora, o que se busca não é a furadeira, mas sim o furo. Se houvesse como se adquirir o furo ao invés da furadeira, o mercado tradicional de furadeiras estaria extinto, novamente excetuando-se profissões específicas que, por exemplo, fornecem furos, ou utilizam deste produto como ferramenta de trabalho.

As relações entre produtos físicos, propriedade individual e personalizada, estão passando por uma profunda evolução. Não queremos o CD; Queremos a música que toca. Nós não queremos o disco. Queremos o armazenamento. Nós não queremos a secretária eletrônica; Queremos as mensagens armazenadas. Nós não queremos o DVD; Queremos o filme. Em outras palavras, queremos não o material, mas as necessidades ou experiências que ele nos proporciona. $^{7}$ (BOTSMAN e ROGERS, 2011, p. 97)

Nesse contexto surge o questionamento, que vai além da possível escassez de recursos financeiros, mas na observância de como empregar os recursos disponíveis. Questiona-se a necessidade de um empresa ter sua sede física, a necessidade de realmente haver um ativo imobilizado, um profissional liberal cuja atividade se assemelha ao freelance ${ }^{8}$, questiona-se as razões de executar o mesmo trabalho mas ter um custo extremamente elevado.

7 The relations between physical products, individual ownership and self-identity is undergoing a profound evolution. We don't want the CD; we want the music it play's. We don't want the disc. We want the storage it holds. We don't want the answering machine; we want the messages it saves. We don't want the DVD; we want the film it carries. In other words, we want not the stuff but the needs or experiences it fulfils.

${ }^{8}$ Freelance se refere a um trabalhador autônomo, independente, principalmente escritor, músico, jornalista, artista etc. que não está empregado permanentemente em nenhuma 
Há ainda que se levantar outras questões que determinam o ambiente que se apresenta como favorável, pois, a partir do momento que a atividade cresce, preconceitos, tanto do profissional como do cliente, acabam caindo por terra.

Como alhures dito, somente n Brasil, segundo o Censo Coworking 2017 acima citado, existem mais de 56 mil postos de trabalho, esse número em 2016, segundo a mesma pesquisa ${ }^{9}$, não chegava a 10mil, número esse que em 2016 já representava um crescimento de 54\% em relação à 2015.

Após um significativo crescimento de 54\%, entre 2015 e 2016, a atividade atinge sua curva exponencial e 540\%, o crescimento de 2016 para 2017 simplesmente é 10 vezes maior do que o excelente crescimento registrado no ano anterior, pela mesma pesquisa.

Mesmo se for considerado que provavelmente a pesquisa na verdade ampliou sua abrangência, passando a identificar mais estações de trabalho, há que se considerar que mesmo que o índice tivesse se mantido (54\%) isto já representaria um excelente crescimento.

Vale ainda ressaltar que uma única estação de trabalho não atende necessariamente um mesmo usuário, sendo inclusive esta a natureza do coworking, que pela própria gênese nasce da ideia do compartilhamento, portanto, numa ideia simples de que 5 pessoas possam se utilizar de uma mesma estação, o contingente de profissionais e empresas que se servem dessa atividade é algo que não se pode desconsiderar.

Começou no final dos anos 2000. Matt Barrie estava irritado. Um capitalista de risco e empresário com experiência em segurança da informação, Barrie estava codificando um site e tentando contratar alguém - qualquer pessoa - para fazer alguma entrada básica de dados. Suas propostas eram decentes. Ele estava disposto a pagar dois dólares por linha para o irmãozinho ou irmãzinha de um amigo. Mas havia aulas de futebol, provas. Todo o processo foi se arrastando por meses, e não estava funcionando.

empresa específica, mas é contratado para fazer diferentes serviços para várias empresas. A origem da palavra vem dos tempos medievais, quando um cavaleiro mercenário tinha sua lança livre, free lance, ou seja, era livre para oferecer seus serviços para qualquer pessoa disposta a pagar por eles. Fonte: http://www.teclasap.com.br/freelance/ - Acesso em 28 jul 2017

${ }^{9}$ Censo Coworking 2016 - Disponível em: https://coworkingbrasil.org/censo/2016/ Acesso em 29 jul. 2017. 
"Frustrado", diz Barrie, "fiquei online e postei o emprego em um site chamado 'Get a Freelancer'. Três horas depois, voltei ao meu computador e encontrei setenta e quatro e-mails de pessoas dispostas a fazê-lo em qualquer lugar, de cem dólares a mil. Contratei uma equipe no Vietnã que terminou o trabalho em três dias. Foi perfeito. Eu não tinha que pagar até que tudo estivesse pronto. Todo o processo foi

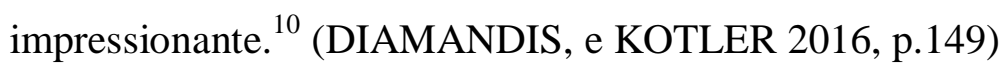

Evidentemente, ainda era cedo para se falar em coworking na acepção atual da palavra, mas houve um trabalho em colaboração, devidamente remunerado, que dispensou burocracias atinentes à contratação, e ainda permitiu que indivíduos residentes do outro lado do mundo, prestassem seus serviços a cliente que, em situações normais e até por questões imigratórias não poderia contratá-los.

Assim, o ambiente que se desenha favorece a colaboração, favorece a prestação de serviços sem vínculos, soma-se tais fatos ao fenômeno do coworking e as variáveis estão resolvidas. O time contratado no Vietnam poderia utilizar um espaço compartilhado para prestar o serviço em colaboração, e este espaço serviria também para ampliar a rede de contatos desse time com os demais profissionais que frequentassem o mesmo espaço.

Vale esclarecer que existem espaços que atendem nichos específicos de profissionais, ambientes que permitem o desenvolvimento de empresas, que por questões de investimentos optam por não ter estruturas físicas, e existem os mais comuns que tratam-se de escritórios compartilhados, salas de aula, salas de atendimentos, onde são fornecidos endereço de correspondência, serviços de secretária, eventualmente ramal telefônico, acesso à internet, etc.

\footnotetext{
${ }^{10}$ It started in the late 2000s. Matt Barrie was irritated. A venture capitalist and entrepreneur with expertise in information security, Barrie was coding a website and trying to hire someone-anyone-to do some basic data entry. His rates were decent. He was willing to pay two dollars a line to the kid brother or kid sister of a friend. But there was soccer practice. There were exams. The whole process dragged on for months. It wasn't working at all. "In frustration" says Barrie, "I got online e posted the job on a site called Get a Freelancer. Three hours later, I came back to my computer and found seventy-four emails from people willing to do it for anywhere from a hundred dollars to a thousand. I hired a team in Vietnam that finished the job in three days. It was perfect. I didn't have to pay them until everything was done. The whole process was mind-blowing.
} 
Sendo que o profissional, dependendo das regras do espaço faz pagamentos de acordo com o tempo que utilizará o ambiente, ou contrata pacotes semanais ou mensais.

Essa nova realidade laborativa facilita inclusive a flexibilização de horários, bem como a possibilidade de o profissional ou a empresa desenvolver suas atividades em localidades diferentes, uma vez que além das conexões estimuladas entre os utilizadores do ambiente, há também um rede que organiza os espaços de coworking, sendo possível a um profissional, por exemplo, da advocacia, ter condições de ter um escritório para atender seus clientes em diversas cidades, sempre a necessidade de qualquer despesa com a estrutura física destes ativos imobilizados.

Os mesmo autores Peter H. Diamands e Steven Kotler (2012) escreveram a obra "Abundância: o futuro é melhor do que você pensa", e, em suas notas iniciais, trazem a seguinte reflexão:

O século 20, por exemplo, testemunhou avanços incríveis e tragédias indizíveis. A epidemia de gripe de 1918 matou 50 milhões de pessoas. A Segunda Guerra Mundial matou outras 60 milhões. Ocorreram tsunamis, furacões, terremotos, incêndios, inundações, até pragas de gafanhotos. Apesar dessas perturbações, esse período também viu a mortalidade infantil cair $90 \%$, a mortalidade materna cair $99 \%$ e, no todo, a expectativa de vida humana aumentar mais de 100\%. Nas duas últimas décadas, todos os países experimentaram enormes distúrbios econômicos. Mesmo assim, hoje em dia até os mais pobres têm acesso ao telefone, à televisão e a vasos sanitários com descarga - três luxos que nem os mais ricos podiam imaginar na virada do último século. $\mathrm{Na}$ verdade, como logo ficará claro, por quaisquer parâmetros disponíveis, a qualidade de vida melhorou mais no último século do que em qualquer outra época. Assim, ainda que ocorram muitas interrupções violentas e angustiantes ao longo do caminho, os padrões de vida globais continuarão melhorando, independentemente dos horrores que dominarem as manchetes. (DIAMANDIS, e KOTLER 2012, p. 9/10) 
Este é o contexto favorável que ambienta a colaboração, a solidariedade e a esperança que a escassez será convertida em abundância face o aumento exponencial das oportunidades, a desburocratização das relações de trabalho, não apenas de empregabilidade mas sim do próprio exercício de profissões.

Um novo capitalismo surge no século XXI animado por uma redução radical nos custos de coordenação numa variedade impressionante de atividades humanas. A colaboração no mercado chegará a níveis inéditos, privilegiando o acesso compartilhado em detrimento da propriedade pura e simples. O capitalismo se reinventa valorizando uma nova forma de coletivismo. Torna-se possível a partir de agora um novo modelo de relacionamento humano onde a cooperação livre e a criatividade responsável têm o potencial de formar o núcleo de um novo paradigma de criação de riqueza. riqueza (GANSKY, 2011, p. $\mathrm{XV})$.

Mesmo em ambiente extremante favorável não se pode desconsiderar as resistências sociais:

O empecilho, contudo, é que, tenha ou não sido moldado pela decisões de nossos ancestrais, nosso mundo de começo do século XXI não é favorável a uma coexistência pacífica, e muito menos à solidariedade humana e à cooperação amigável. Ele foi moldado de tal forma que torna a cooperação e a solidariedade não apenas uma escolha impopular, como também difícil e onerosa, e em relativamente poucas ocasiões, considerem que esteja em seu poder material e/ou espiritual fazer essa opção e deslindar seu verdadeiro sentido. (BAUMAN, 2015, p.37)

Uma nova classe de empreendimentos surge, mesmo nesse aparente paradoxo, há uma resposta que remonta uma nova realidade que mesmo dentro de uma organização capitalista traz o compartilhamento como meio de crescimento. 
Nos últimos dois séculos, a economia industrial recompensou um tipo de específico de capitalista. Sobreviver e prosperar envolvia se tornar só um pouquinho menor que um monopólio, controlando o mercado ao mesmo tempo em que evitada a regulamentação. $\mathrm{O}$ controle ela mantido pela detenção exclusiva de propriedade intelectual, segredos comerciais, direito autorais, equipamentos e funcionários. Por quê? Porque fábricas, ferramentas e outros meios dispendiosos de produção exigiam organizações grandes o suficiente para extrair todo o seu potencial. Produtos e serviços eram padronizados porque grandes volumes levavam a economias de escala e a capacidade de oferecer produtos a preços mais baixos. Maiores volumes também traduziam em uma maior participação de mercado.

E de repente a internet entra na equação.

Aquelas velhas barreiras à entrada - grandes ativos de capital fechado e propriedade intelectual fechada - deixam de resultar no maior valor. Acabam sendo estratégias datadas, incapazes de corresponder ao potencial encontrado nos atuvos compartilhados, que sempre oferecerão retornos melhores e colocarão o poder nas maões de multidões que representam pools intelectuais infinitamente maiores. Assim, no mundo todo, o poder está passando de entidades morosas, fechadas e centralizadas ao modelo da Peers Inc, ágil, adaptável e distribuído. É assim que as organizações da Peers Inc começam a reinventar o capitalismo. (CHASE, 2015, p.288)

Novos caminhos surgem: "Essa parte da história, que agora chega ao fim, poderia ser chamada de, na falta de nome melhor, de era do hardware, ou modernidade pesada" (BAUMAN, 2001, p.144)

[...] a passagem da fase "sólida" da modernidade para a "líquida" - ou seja, para uma condição em que as organizações sociais (estruturas que limitam as escolhas individuais, instituições que asseguram a 
repetição de rotinas, padrões de comportamento aceitável) não podem mais manter sua forma por muito tempo (nem se espera que o façam), pois se decompõem e se dissolvem mais rápido que o tempo que leva para moldá-las e, uma vez reorganizadas, para que se estabeleçam. É pouco provável que essas formas, quer já presentes ou apenas vislumbradas, tenham tempo suficiente para se estabelecer, e elas não podem servir como arcabouços de referência para as ações humanas, assim como para as estratégias existenciais a longo prazo, em razão de sua expectativa de vida curta: com efeito, uma expectativa mais curta que o tempo que leva para desenvolver uma estratégia coesa e consistente, e ainda mais curta que o necessário para a realização de um "projeto de vida" individual. (BAUMAN, 2007, p.07)

Este portanto é o que se pode chamar de contexto social, ou ambiente favorável para que o acesso sobreponha a propriedade, e tal mentalidade torna-se terreno fértil para que possa-se abrir espaço à colaboração. Considerando a complexidade social no qual está inserido, ensejando uma releitura da atividade empresarial segundo as complexidades sociais e que os avanços tecnológicos, bem como a necessidade de solidariedade se efetive.

Nesse sentido Edgar Morin, aduz a importância de se considerar que "A sociedade é um "complexo" no sentido da palavra latina complexus, que significa "o que é tecido em conjunto; se seguirmos os fios energéticos, chegaremos ao complexo de conjunto." (MORIN, 2013. p.44). Nota-se, portanto, que considerar uma visão reducionista e mitigada da cooperação e o envolvimento para o desenvolvimento, que não contemple toda a complexidade social, seria um ensejo a falta de propósito.

Dentro da sociedade, faz-se necessário que os indivíduos atuem de forma organizada e colaborem entre si, viabilizando a sobrevivência e a evolução do grupo, de onde se depreende a noção da solidariedade. (SANTIAGO, 2.017, p. 191)

Profissionais de diversas áreas que não tenham que se preocupar com a administração de seus escritórios, consultórios, laboratórios, oficinas, etc., nem como os 
colaboradores que tais empreendimentos demandam, podem focar em suas atividades, otimizando recursos financeiros, e ampliando o leque de opções em razão da rede profissional multidisciplinar facilitada pelos espaços compartilhados, bem como a própria rede existente entre os espaços de coworking.

\section{RELAÇÕES JURÍDICAS AFETAS AO COWORKING}

Levanta-se algumas possibilidades de afetação jurídica, sob o prisma de legislação em vigor que pode ser considerada como aplicável às relações em ambientes de coworking, seja entre os profissionais, nas relações havidas entre os usuários e as empresas que disponibilizam os espaços, ou ainda afetas aos clientes que utilizam dos serviços prestados por profissionais ou empresas instaladas em coworkings.

Em primeiro momento a questão contratual há que ser sopesada, em que pese haver liberdade para que profissionais e empresas de áreas totalmente distintas, o que inclusive é estimulado, trabalhem juntos, é importante que se determine como profissionais ou empresas, como sendo quem exerce atividade lícita.

Ora, mesmo havendo certa liberdade na contratação, é de suma importância que o responsável pelo espaço saibas das atividades que ali são desenvolvidas, evidentemente que, ao se tratar de afetações jurídicas havidas entre profissionais e empresas que utilizam esses espaços compartilhados já se subentende que tratam de atividades regulamentadas, não se espera que, por exemplo, um traficante de drogas, utilize o espaço para ter um contato mais "profissional” com seus “clientes”, uma vez que que os próprios termos: profissão, cliente, etc somente são utilizados quando trata-se realmente de profissões, e atividades que são lícitas.

Entretanto alguns criminosos podem se aproveitar do ambiente compartilhado com escopo de disfarçar práticas ilegais.

Como exemplo pode-se citar o exercício ilegal de profissão, capitulado no art. 47 da Lei das Contravenções Penais.

Art. 47. Exercer profissão ou atividade econômica ou anunciar que a exerce, sem preencher as condições a que por lei está subordinado o seu exercício. 
Em um espaço de coworking voltado para o nicho da advocacia, ainda a título de exemplo, um profissional, ainda estagiários, habilitado junto à Ordem dos Advogados do Brasil, se apresenta a seus "clientes" como advogado, e em razão até do princípio da aparência é visto por quem o contrata como habilitado para a prática da advocacia. Evidentemente é um dos cuidados que a empresas que organiza o espaço é responsável, uma vez que se propôs a manter um ambiente voltado à um nicho específico, há que averiguar se os usuários realmente são credenciados.

O mesmo ocorre se for ser considerado o crime capitulado no Art. 282 do Código Penal, que assim prevê:

Art. 282 - Exercer, ainda que a título gratuito, a profissão de médico, dentista ou farmacêutico, sem autorização legal ou excedendo-lhe os limites:

Ora, observe-se que a legislação capitula como fato típico até o exercício à título gratuito, então, novamente, há que se observar que um espaço de coworking voltado para o nicho da medicina, odontologia, farmácia, etc, também precisa verificar o registro dos usuários afim de evitar que o ambiente se torne local para prática de crimes, o que desvirtua por completo a relação colaborativa que deve reger o espaço.

Em se tratando se um espaço múltiplo, onde diversos profissionais utilizam-se do espaço, o que é a verdadeira natureza do coworking, não de descaracterizando os espaços compartilhados como tal, mas nos casos da utilização por profissionais de áreas diferentes, empresas, etc, há também a preocupação dos organizadores do espaço em contratar, de forma a se resguardarem de qualquer ilicitude, em que pese a popularização de tais modalidades facilitam a interpretação legal capaz de afastar a responsabilidade cível ou criminal.

Neste aspecto há que se trazer a previsão contida no Código Civil, no que concerne à atribuição de responsabilidade:

Art. 927. Aquele que, por ato ilícito (arts. 186 e 187), causar dano a outrem, fica obrigado a repará-lo.

Parágrafo único. Haverá obrigação de reparar o dano, independentemente de culpa, nos casos especificados em lei, ou 
quando a atividade normalmente desenvolvida pelo autor do dano implicar, por sua natureza, risco para os direitos de outrem.

Nesse contexto o espaço de coworking deve possuir documentação capaz de excluir qualquer responsabilidade que ao empreendimento possa ser imputada no que concerne à prestação de serviço ou atividade desempenhada pelo profissional ou empresa que utiliza-se do espaço, sendo evidente que a própria existência do empreendimento trata-se de um negócio que como qualquer atividade econômica possui seus riscos, portanto, nesse quesito ainda se aborda somente a possibilidade ou impossibilidade de se atribuir ao organizador do coworking responsabilidade pelo trabalho que fora realizado em seu espaço.

Assim, afim de se afastar a responsabilidade faz-se necessário como dito, um ato de vigilância, mesmo que não ostensiva, mas documental exigível ao detentor no negócio, afim de que não restem configurados os elementos imprescindíveis à obrigatoriedade de reparação de dano, quais sejam: ato lesivo, dano, culpa e nexo causal.

No que concerne à relação entre os utilizadores do espaço de coworking e das próprias empresas que disponibilizam o espaço, abre-se espaço para se discutir a aplicabilidade ou não do Código de Defesa do Consumidor nessa relação.

Há que se ressaltar que a figura do consumidor recebeu no texto constitucional especial proteção sendo elevada a proteção ao consumidor à categoria de princípio, sendo expresso no inciso XXXII que o Estado promoverá a defesa do consumidor, somando-se à previsão contida no Art. 24 da mesma Constituição Federal de 1.988, quando traz as determinações legislativas que competem aos entes federados, em seu inciso VIII:

VIII - responsabilidade por dano ao meio ambiente, ao consumidor, a bens e direitos de valor artístico, estético, histórico, turístico e paisagístico (BRASIL, CF, 1988) (grifo nosso).

Ainda nos princípios da ordem econômica é prevista a defesa do consumidor expressamente no inciso V do Art. 170, cumprindo transcrever:

Art. 170. A ordem econômica, fundada na valorização do trabalho humano e na livre iniciativa, tem por fim assegurar a todos existência 
digna, conforme os ditames da justiça social, observados os seguintes princípios:

$[\ldots]$

V - defesa do consumidor; (BRASIL, CF, 1988).

Assim, com a previsão constitucional, surge em 11 de setembro de 1.990 a Lei n. 8.078, que recebeu a nomenclatura de Código de Defesa do Consumidor, afim de não deixar dúvidas sobre sua natureza protecionista.

Entrementes, para que possa-se ser destinatário dessa proteção, exige-se a presença de pré-requisitos:

O CDC incide em toda relação que puder ser caracterizada como de consumo. Insta, portanto, que estabeleçamos em que hipóteses a relação jurídica pode ser assim definida [...] haverá relação jurídica de consumo sempre que se puder identificar num dos polos da relação o consumidor, no outro, o fornecedor, ambos transacionando produtos e serviços (NUNES, 2017, p. 118).

A definição de consumidor e fornecedor são apresentadas e definidas expressamente na legislação:

Art. $2^{\circ}$ Consumidor é toda pessoa física ou jurídica que adquire ou utiliza produto ou serviço como destinatário final.

Parágrafo único. Equipara-se a consumidor a coletividade de pessoas, ainda que indetermináveis, que haja intervindo nas relações de consumo

Art. $3^{\circ}$ Fornecedor é toda pessoa física ou jurídica, pública ou privada, nacional ou estrangeira, bem como os entes despersonalizados, que desenvolvem atividade de produção, montagem, criação, construção, transformação, importação, exportação, distribuição ou comercialização de produtos ou prestação de serviços. 
$\S 1^{\circ}$ Produto é qualquer bem, móvel ou imóvel, material ou imaterial.

$\S 2^{\circ}$ Serviço é qualquer atividade fornecida no mercado de consumo, mediante remuneração, inclusive as de natureza bancária, financeira, de crédito e securitária, salvo as decorrentes das relações de caráter trabalhista (BRASIL, Lei n. 8.078 de 11 de setembro de 1.990).

Portanto, havendo um consumidor e um fornecedor e a transação envolvida se caracterizar como relação de consumo aplica-se os institutos trazidos pela legislação consumerista.

Assim a relação entre os usuários de ambientes de coworking e seus clientes serão caracterizadas como relação de consumo dependendo do preenchimento dos requisitos, entrementes o que importa à este estudo, que lança um olhar sobre tal modalidade laborativa sob o prisma da legislação pátria é identificar se há ou não relação de consumo e se quem utiliza o espaço e quem o disponibiliza se encaixam como consumidores e fornecedores.

E ao se deparar com a legislação em vigor evidencia-se que se caracteriza uma relação de consumo, de modo a ser aplicado o Código de Defesa do Consumidor, de modo à proteger essa relação, uma vez que a estação de trabalho como produto e os diversos outros serviços são fornecidos pelo organizador do espaço, bem como os usuários se caracterizam como consumidores finais de tais produtos e serviços.

Enquanto atividade legalizada outras relações jurídicas podem afetar os espaços de coworking, cumprindo à quem se propõe operacionalizar tais empreendimentos ou se utilizar deles se precaver de responsabilidades que extrapolem o exercício normal de suas profissões com fincas a utilizar esta nova modalidade como meio de agregação de valor, potencialização do ócio, ampliação de redes de contatos profissionais, compartilhamento de ideias e recursos, e não para se ver diante de uma situação que possa imputar à quaisquer das partes envolvidas responsabilidades que não são relativas às atividades exercidas.

\section{CONSIDERAÇÕES FINAIS}

Observa-se que a pretensão do presente trabalho fora alcançada no sentido de possibilitar um olhar macro sobre uma atividade que vem crescendo exponencialmente e se mostra não somente como uma oportunidade para se laborar de forma não tradicional mas 
também como uma excelente oportunidade de negócio para que se propõe a organizar tais espaços.

Apresenta-se o histórico afim de se observar que não se trata de algo que possui passado remoto, em que pese o compartilhamento de espaços ser uma realidade antiga, a disponibilização de estações de trabalho a valorização da colaboração, e o incentivo à interdisciplinaridade são elementos que se popularizaram recentemente.

O ambiente é favorável, a época é propícia a valorização do acesso sobre a propriedade vem ganhando força, somado à tal propagada potencialização do ócio, que é motivada pela economia compartilhada, colaborativa e disruptiva, que visa quebrar certos padrões que por si só vão perdendo o sentido.

A tônica do momento é a criatividade. Se é possível evitar a ativo imobilizado concentrando-se as forças e recursos da empresa apenas no real propósito da mesma, os ambientes de coworking também não se encontram engessados à um modelo único, sendo espaços que estimulam à inovação.

Lançando-se um olhar jurídico sobre o tema, faz-se importante destacar que a relação há que ser lícita, pois sem a o caráter da licitude sequer pode-se falar em exercício de profissão ou atividade econômica, entretanto, há que se abrir espaço para analisar a possibilidade de exercício ilegal de profissão, assim obriga-se o empreendedor que organiza o espaço de coworking, promover contratações precisas, e decidir sobre ter seu espaço voltado á algum nicho específico ou não, sendo certo que mesmo o espaço não especializado, depende da atuação ostensiva o proprietário, ou administrador, como regulador das atividades ali desempenhadas.

Outra questão relevante é a responsabilidade civil, que também deve ser resguardada por quem detém tais espaços afim de haver documentação suficiente capaz de afastar qualquer imputação que extrapole à relação havida entre as partes.

Relação esta que conforme se demonstrou trata-se de relação de consumo merecedora de toda a proteção trazida desde o texto constitucional, até a legislação consumerista específica, vez que presentes os pré-requisitos necessários.

Assim, há que se observar por derradeiro que a legislação pátria aplicável às questões ora estudadas, em que pese não ser de produção recente atendem o fim que se propõe não havendo demanda à novos ordenamentos, sendo certo que, como entende-se desde os primórdios Bíblicos, é a Lei feita para o homem e não o contrário. 
Portanto é de suma importância que a produção legislativa não busque acompanhar qualquer modernização, mas se comporte como pacificadora social e atenda o verdadeiro detentor do poder democrático que é o povo.

\section{REFERÊNCIAS BIBLIOGRÁFICAS}

BAUMAN, Zygmunt. A Riqueza de poucos beneficia todos nós? Tradução: Renato Aguiar Rio de Janeiro, Zahar Ed. 2015.

BAUMAN, Zygmunt. Modernidade Líquida. Tradução: Plínio Dentzien - Rio de Janeiro, Zahar Ed. 2001.

BAUMAN, Zygmunt. Tempos líquidos. Tradução: Carlos Alberto Medeiros - Rio de Janeiro: Jorge Zahar Ed. 2007.

BLOG, Coding in Paradise. Disponível em <blog.codinginparadise.org> Acesso em 25 de julho de 2.017

BRASIL, Código Penal, Decreto Lei 2.848 de 7 de dezembro de 1.940. Disponível em: < http://www.planalto.gov.br/ccivil_03/decreto-lei/Del2848compilado.htm>. Acesso em: 15 julho de 2017

BRASIL. Decreto Lei n. 3.688 de 3 de outubro de 1.941 - Lei das Contravenções Penais. Disponível em: < http://www.planalto.gov.br/ccivil_03/decreto-lei/Del3688.htm> acesso em 24 de julho de 2.017

BRASIL, Código Civil, Lei n. 10.406 de 8.078 de 10 de janeiro de 2002. Disponível em: < http://www.planalto.gov.br/ccivil_03/leis/2002/L10406.htm>. Acesso em: 15 maio de 2017 BRASIL, Lei n. 8.078 de 11 de setembro de 1.990. Dispõe sobre a proteção do consumidor e dá outras providências. Disponível em: <http://www.planalto.gov.br/ccivil_03/leis/L8078.htm > Acesso em: 15 de maio de 2017 
BRASIL. Constituição da República Federativa do Brasil. Brasília, DF: Senado Federal: Centro Gráfico, 1988. 292 p. BRASIL.

BOTSMAN, Rachel e ROGERS, Roo. Whats mine is yours - How collaborative consumption is changing the way we live. Ed. Collins, London-UK, 2.011.

CHASE, Robin. Economia Compartilhada - Como pessoas e plataformas da Peers Inc. estão reinventando o capitalisto. Ed. HSM, São Paulo, 2.015.

COWORKING, Censo 2016 - Disponível em https://coworkingbrasil.org/censo/2016/ Acesso em 15 de julho de 2.017

COWORKING, Censo 2017 - Disponível em https://coworkingbrasil.org/censo/2017/ Acesso em 15 de julho de 2.017

COWORKING, The Start of (from the Guy that Started It). Disponível em <http://codinginparadise.org/ebooks/html/blog/start_of_coworking.html > Acesso em: 25 de julho de 2.017

DIAMANDIS, Peter H. e KOTLER, Steven. Abundância - O Futuro é melhor do que você imagina (Abundance: the future is better than you think), tradução IVO Korytowski, Ed. HSM, São Paulo, 2012.

DIAMANDIS, Peter H. e KOTLER, Steven. BOLD - How to go big, create wealth, and impact the world. Ed. Simon \& Schuster Paperbacks, New York, 2016.

GANSKY, Lisa. Mesh Porque o futuro dos negócios é compartilhar, Ed. Alta Books, Rio de Janeiro, 2011.

LINKEDIN. Brad Neuberg. Disponível em <https://www.linkedin.com/in/bradneuberg/> Acesso em 26 jul 2.017

MORIN, Edgar. A Via para o futuro da humanidade. Rio de Janeiro: Bertrand Brasil, 2013.

NUNES, Rizatto. Curso de direito do consumidor. 11. ed. São Paulo: Saraiva, 2017.

SANTIAGO, Mariana Ribeiro. O Direito Civil sob a ótica da solidariedade social. in Direito e Solidariedade, Editora Juruá, Curitiba, 2017;

SAP, Tecla. Freelance. Disponível em <http://www.teclasap.com.br/freelance/> - Acesso em 19 de julho de 2.017 